https://doi.org/10.48009/1_iis_2007_8-14

\title{
THE GEOGRAPHIC INFORMATION SYSTEMS INITIATIVE AT THE NORTHERN ILLINOIS UNIVERSITY COLLEGE OF BUSINESS
}

\author{
Richard G. Born, Northern Illinois University, rborn@niu.edu \\ Brian Mackie, Northern Illinois University, bmackie@niu.edu
}

\begin{abstract}
It is estimated that $80 \%$ of all corporate data has content that is geographic, meaning that place or location can be associated with the data. This fact is leading innovative businesses worldwide to treat geographic data as an organizational asset and to realize that location information about customers, suppliers, and competitors can be a key business driver. It is within this context that the College of Business at Northern Illinois University (NIU) has, for the past eight years, offered both undergraduate and graduate students the opportunity to learn business applications of geographic information systems. This paper describes this initiative, emphasizing the kinds of location-based business problems solved by students.
\end{abstract}

Keywords: Business Applications of Geographic Information Systems (GIS), Location-based Systems (LBS), Net Centric Computing, Wireless and Mobile Computing, Microsoft ${ }^{\circledR}$ MapPoint ${ }^{\mathrm{TM}}$ Technologies, ESRI ArcView ${ }^{\circledR}$, Intergraph GeoMedia

\section{INTRODUCTION}

Keeping today's business leaders informed about key emerging technologies for business analysis has lead the College of Business at NIU to develop a geographic information systems initiative. This process began back in 1996 when the Department of Operations Management and Information Systems (OM\&IS) worked jointly with the Department of Geography (GEOG) to get a program in business geographics started. This relationship was an essential seed for the overall success of this program. Business schools interested in starting such an initiative are encouraged to seek support from their geography departments, as provosts are generally quite receptive to hearing of programs that are interdisciplinary in nature.

OM\&IS at NIU's College of Business has established two courses in which business applications of geographic information systems are taught, one at the undergraduate level and another at the graduate level. As of the spring 2007 semester, nearly 300 students have taken these classes. Seeing the value of these business geographics courses to students of geography as well as business students, GEOG has included the undergraduate business geographics course as an elective in its Certificate of Undergraduate Study in Geographic Information Systems. The undergraduate business geographics course has seen an increasing number of geography student enrollments over the past three years, with GEOG students generally feeling a significant increase in employment possibilities as a result of exposure to business applications of GIS.

The business geographics courses have evolved significantly since their inception in 1999. Originally, the courses made use of Intergraph's Modular Geographic Information Systems Environment (MGE) software and were supported by a 24 personal computer lab donation from Intergraph Corporation. MGE was rapidly replaced by Intergraph's GeoMedia Professional software, and the NIU College of Business received free licenses for this software through its alliance with GEOG. All of this was possible because NIU was recognized as one of six Intergraph Centers of Excellence in the United States, a privilege given only to universities for which multiple departments cooperate and promote student learning of GIS. It seems most appropriate that the two seemingly diverse academic disciplines of geography and business have been able to cooperate to achieve a worthwhile goal for students.

A second corporate alliance, between OM\&IS and Microsoft, has also been evolving since the release of MapPoint [9], Microsoft's first business desktop mapping software. With its interface similar to that of other Microsoft Office products and the ability to integrate MapPoint with those products, business mapping capabilities had begun to reach the masses. Through the Microsoft Development Network Academic Alliance (MSDN AA) program, OM\&IS has received free copies of MapPoint for its computer laboratory as well as for students to install on their own computers to solve assigned business problems. In addition, OM\&IS has received a free, non-expiring account to use in teaching development of Internet 
connected, location-enabled applications that make use of the MapPoint Web Service.

The most recent addition to vendor alliances has been with the Environmental Studies Research Institute (ESRI) and its ArcGIS ${ }^{\circledR}$ products [10]. ESRI has been a well-known leader of GIS software for many years and offers universities 25-user computer laboratory licenses for its ArcView ${ }^{\circledR}$ base product at very reasonable educational pricing.

\section{THE TAXONOMY FOR THE BUSINESS GIS COURSES}

Thota [14] describes a method for classifying location-based applications using MapPoint technologies that forms the foundation for the OM\&IS courses in business GIS. This taxonomy is summarized in Figure 1, which shows four quadrants based upon two dimensions. The first dimension deals with whether or not the application is disconnected or connected to the Internet. The second dimension distinguishes between applications that are location-enabled and those that are real-time, location-aware. Specific characteristics of typical location-based applications are indicated in each of the four quadrants. Note that ESRI ArcView applications in the OM\&IS courses fit into the upperleft quadrant representing disconnected, locationenabled applications. Recently published books, including Schray [11] and Shelly [12] are now beginning to include chapters on location-based, sometimes called mobile applications. Such applications are becoming much easier to develop using products such as Visual Basic 2005, which eliminates the need to have administrative privileges when debugging Web applications as well as the need to have Internet Information Server (IIS) and FrontPage Server Extensions.

\begin{tabular}{|c|c|c|}
\hline & $\begin{array}{c}\text { Location-Enabled } \\
\text { (understand location and how to process it) }\end{array}$ & $\begin{array}{l}\text { Location-Aware (Real-Time) } \\
\text { (application is also aware of its own location) }\end{array}$ \\
\hline $\begin{array}{l}\text { Disconnected } \\
\text { (location information } \\
\text { and processing } \\
\text { framework are all } \\
\text { on the host } \\
\text { computer's } \\
\text { hard disk) }\end{array}$ & $\begin{array}{c}\text { ESRI ArcGIS } \\
\text { MapPoint } \mathbf{2 0 0 6} \\
\text {-Thematic mapping of corporate data } \\
\text {-Corporate territory management } \\
\text {-Demographic mapping of census data } \\
\text {-Determining shortest/fastest routes }\end{array}$ & $\begin{array}{c}\text { MapPoint } 2006 \text { Interfaced } \\
\text { with a GPS Device } \\
\text { •Real-time navigation } \\
\text { •Real-time location-based information logging }\end{array}$ \\
\hline $\begin{array}{l}\text { Connected } \\
\text { (network connectivity } \\
\text { is essential- } \\
\text { location information } \\
\text { and processing } \\
\text { framework are on a } \\
\text { remotely located } \\
\text { host service) }\end{array}$ & $\begin{array}{c}\text { MapPoint Web Service } \\
\text { •Hosted by Microsoft } \\
\text { •Global location-based applications } \\
\text { that work for multiple countries } \\
\text { •Store finder } \\
\text { •Best route to store } \\
\text { •Find competitors } \\
\text {-Maintain custom points of interest }\end{array}$ & $\begin{array}{c}\text { MapPoint Location Server } \\
\text { •Hosted within your enterprise } \\
\text { •Requires IIS (Internet Information Server) } \\
\text { with SSL (Secure Socket Layers) } \\
\text { •Enables real-time location scenarios } \\
\text { using locatable devices } \\
\text { • No GPS hardware/software needed } \\
\text { •Finding nearby ATMs, restaurants, } \\
\text { motels, gas stations } \\
\text { •Calculating driving directions } \\
\text { based on current location } \\
\text { and real-time traffic conditions }\end{array}$ \\
\hline
\end{tabular}

Figure 1. The MapPoint Location-Based Application Taxonomy Used in OM\&IS Business GIS Courses

It can be seen that, with the exception of ESRI ArcGIS in the upper-left quadrant, this taxonomy emphasizes Microsoft MapPoint products in the teaching of business applications of GIS. This is 
justified for a variety of reasons, all of which relate to the nature of the business world [7]. First, Microsoft is targeting the decision makers who are usually at the higher management and executive levels rather than those who create and maintain complex GIS data. Second, Microsoft has the know-how to price its products affordably, especially its MapPoint desktop business mapping software, which is intended for use by the business person with little knowledge about GIS. Students who are trained in the use of the MapPoint desktop product are far more likely to advocate its use in their places of work upon graduation and receive positive corporate response due to the low cost of MapPoint. Third, Microsoft has the know-how to bundle demographic data with software and still keep its MapPoint desktop product affordable. A large variety of demographic information derived from the U.S. census is available in geographies including states, Metropolitan Statistical Areas (MSAs), counties, ZIP codes, and census tracts. Such demographic information is quite valuable in marketing applications including customer profile reports and direct mail campaigns, as well as in planning department applications such as finding suitable sites for new stores, to mention only a few.

\section{BUSINESS GIS COURSE DELIVERY}

Two possible approaches to delivery of the business GIS courses were considered. One is a more traditional textbook-oriented approach. During the past five years a number of books $[5,8,10,13]$, all dealing with ESRI ArcGIS products, have been published that could serve this purpose. All of these books provide good case studies on the use of GIS, some of which include data CDs $[8,10]$. Boyles [5] probably provides the best business related examples, including marketing applications, vehicle routing, territory management, site location, and Internet Map Publishing.

The second approach to delivery of the business GIS courses is a more hands-on approach, in which the students are given real-world data from businesses and organizations with specific business problems requiring GIS-based solutions. This approach requires a great deal of time on the part of the instructor in approaching businesses for possible projects but has been aided by the establishment of a Business Geographics Center at the NIU College of Business. This center and its Web site [4] have actually resulted in a number of companies and organizations proactively contacting the OM\&IS department with projects.
The hands-on, real-world project approach was ultimately selected for delivery of the business GIS courses offered by OM\&IS. Students have found that working with business problems and data supplied by a variety of companies gives the students a feeling of working toward a goal that is difficult to achieve with textbook-based problems. In some cases, students or student teams have had to present their results to the companies in the form of either a presentation or a final printed report. Companies have expressed gratitude for the work done by the students, and in some cases OM\&IS has been able to build long-term relationships with a company or organization.

\section{BUSINESS GIS PROJECTS}

As of the writing of this paper, the great majority of the real-world business GIS projects completed by students lie in the upper-left quadrant of the taxonomy - disconnected, location-enabled. More recently, due to the development of the MapPoint Web Service Helper [3], some projects have been added that fall into the lower-left quadrant connected, location-enabled. MapPoint Web Service Helper has been a joint effort between OM\&IS and Microsoft, and is now available to university faculty through the MSDN AA Academic Resource Center. This section of the paper will briefly describe some of the major real-world business GIS projects. For each project there will also be a short discussion of the GIS concepts learned. First, some ArcGIS disconnected, location-enabled projects are discussed. This will be followed by a discussion of some MapPoint disconnected, location-enabled projects. The decision as to whether a project uses ArcGIS or MapPoint software is driven by a number of factors, the most prominent being which product is available at the sponsoring company or organization. Finally, there will be a discussion of recent connected, location-enabled projects that have been added to the course.

\section{ArcGIS Disconnected, Location-enabled Projects}

Rockford MidTown District (MTD). The MTD is both a region in Rockford, IL, and an agency established to make the district a safe and enjoyable place to live as well as operate a business. MTD asked the NIU College of Business, through its Business Geographics Center and Business Information Technology Transfer Center, to help MTD develop a business GIS that would aid in trending, forecasting, and justifying its marketing and development plans. Students created residential maps that showed tremendous variability in singlefamily vs. multi-family homes as one traveled from 
the North to the south end of MTD. Understanding this variability was a key to creating programs to facilitate home ownership by offering financial assistance. Students also created business classification maps that were important in attracting more businesses, thus increasing money that comes into the neighborhood. Finally, the students produced a map shown in Figure 2 that showed crime incidents on a block-by-block basis from data supplied by the Rockford Police Department. These maps, when created with new data every year, are helpful to MTD in assessing the effect of social programs designed to reduce crime rates. The greatest lesson learned by everyone involved with this project was that the most difficult part of developing any business GIS system is obtaining the data from the constituent parties. For the MTD project data came from county and city government as well as from police departments and a number of other agencies.

\section{Crime Patterns in Central Rockford, IL}
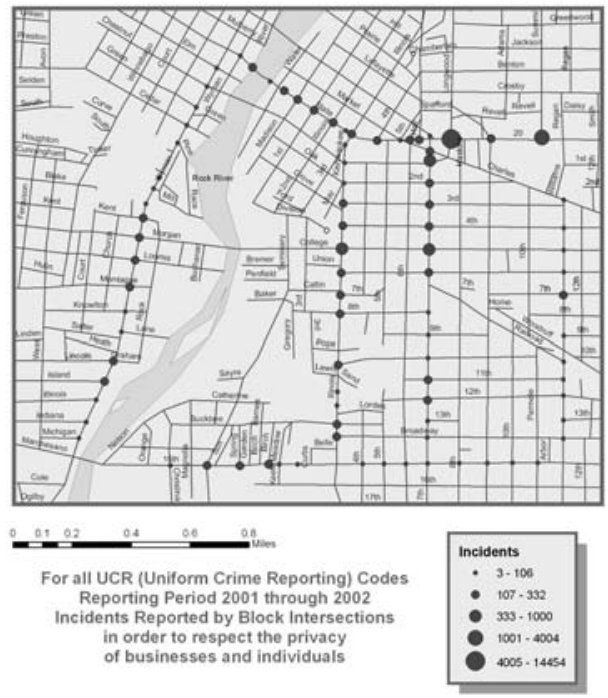

Figure 2. Crime Patterns Near the MidTown District

Bridges of RiverMist (BRM). BRM is a relatively new subdivision in the city of DeKalb, IL. Interested in producing some maps to be used in marketing their lots on the Web, BRM supplied our students with an engineering drawing of one of their neighborhoods as well as attribute data on available lots. From this drawing and from global positioning system (GPS) data collected on some lot boundaries, the students were able to create the map of Figure 3 showing lot price, lot type, and lot size. Learning activities included the use of GPS devices for collection of latitude/longitude data, heads-up digitization of streets, ponds, and parcels, and joining corporate attribute data such as lot type and price to geographic parcels.
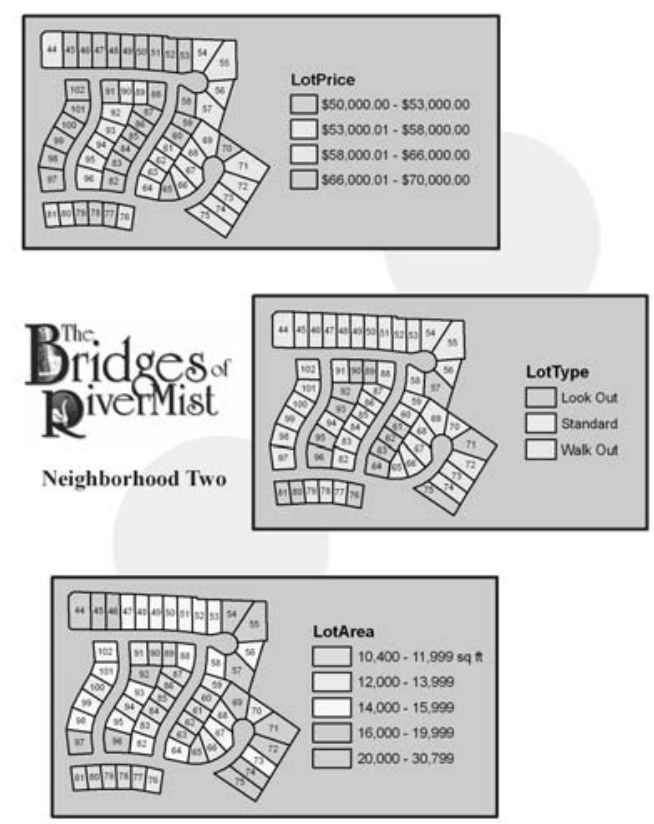

Figure 3. Bridges of RiverMist Marketing Maps

Family Shelter Services (FSS). FSS is an organization in DuPage County, Illinois, that provides shelters offering immediate safety for domestic violence victims and their children. Many programs are available through FSS, including a 24hour hotline, individual counseling for all victims, support groups, court advocates, children's program counselors, medical advocates, and a teen program. The success of FSS has resulted in their need to open another shelter to serve its increasing clientele, but FSS was not sure of where the best location would be for this new shelter. They provided OM\&IS students with anonymous data on the city in which each of their clients lives and asked that a map be constructed that would provide general potential locations for the new shelter. This map, shown in Figure 4, required students to perform a number of common GIS operations including joining attribute data to spatial data and clipping features to boundaries of other features. Students also learned how to work with State Plane projected coordinate systems and how to create map annotations from map labels. In addition, students learned how to create map layers, including counties, cities where FSS clients live, and major roads. Finally, students learned how to use graduated symbols showing the number of FSS clients by city. A side benefit of this project was that students had to 
learn how to do some preprocessing of the FSS data using the pivot table feature of Excel.

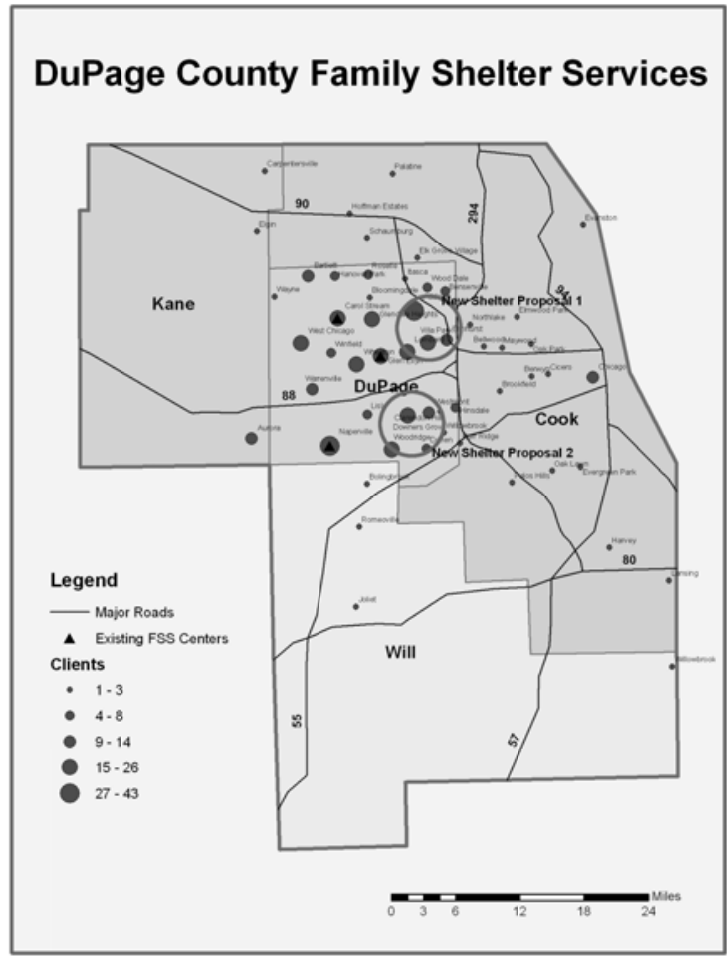

Figure 4. Potential Locations for a New FSS Shelter

Targeting New Walgreens Locations [2]. The Walgreen Company has partnered with OM\&IS for several years, offering speakers to classes on how they use GIS in Market Planning and Research, especially in targeting potential locations for new stores. Students have worked in teams to develop a model based upon a variety of block-group demographic statistics and an internally supplied Walgreen rating of pharmacy demand for each block group. Students investigated intersections with high average daily traffic counts that were not too close to existing Walgreen stores and had a low number of nearby competitors.

\section{MapPoint Disconnected, Location-enabled Projects}

Planned Parenthood Advocacy Maps (PPA). Planned Parenthood is an advocate of reproductive rights and health issues wherever public policy is discussed. OM\&IS was contacted by the Illinois area PPA requesting that we help them produce some maps. By mapping the locations of their existing advocates respective to U.S. congressional districts and state legislative (state House and Senate) districts, they can better focus their marketing efforts to potential advocates in key political districts throughout the state. Visually understanding where their current advocates live and where they lack presence in key districts will help them focus their messages to potential new advocates. This project required students to geocode advocate addresses and import, via a COM (Component Object Mode) add-in [1], legislative boundaries into MapPoint. An example map is shown in Figure 5.

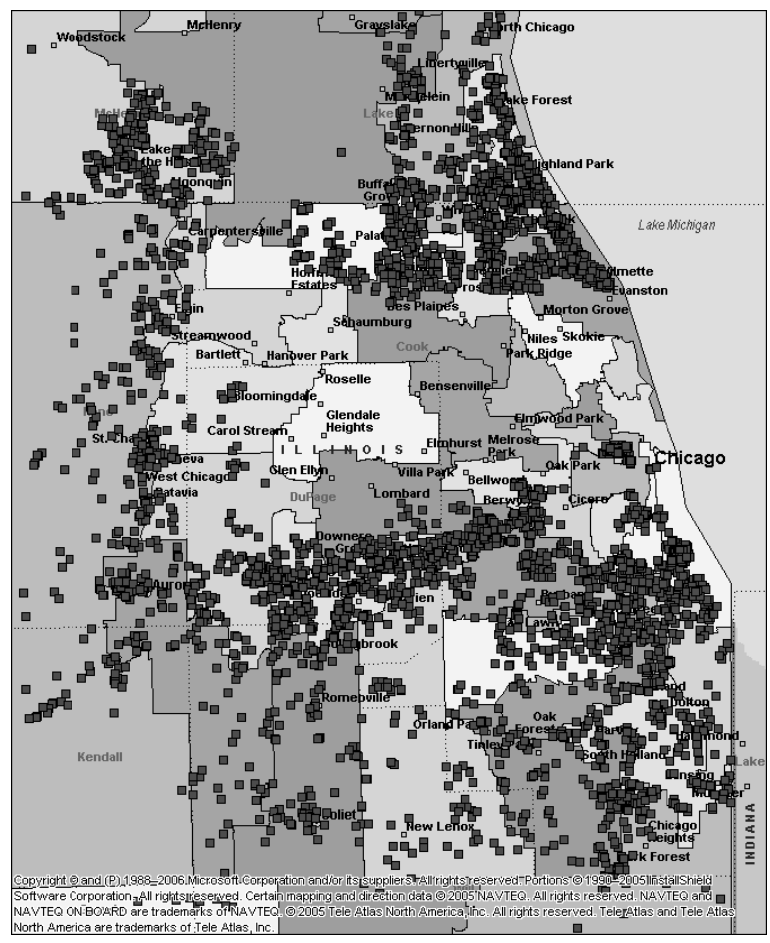

Figure 5. PPA Clients by Illinois State Senate Districts.

Affordability of Homes in Kane and McHenry Counties of Illinois [6]. The real estate industry compiles much data on homes sold in various localities. Affordability of homes is a concern to everyone in the market when buying a home. One could reasonably define affordable as any home selling for less than or equal to the median selling price. Any homes selling for greater than the median selling price would then be classified as not affordable. The project sponsor and students found it particularly interesting to note the existence (or lack thereof) of clusters of affordability (white pushpins in Figure 6) and non-affordability (dark pushpins). Students learned how to import an Access database into MapPoint and how to aggregate and summarize large quantities of data by creating shaded area maps showing the average selling price of homes by Census tracts. In addition, students learned how to 
geocode addresses and display them as pushpins in a map.

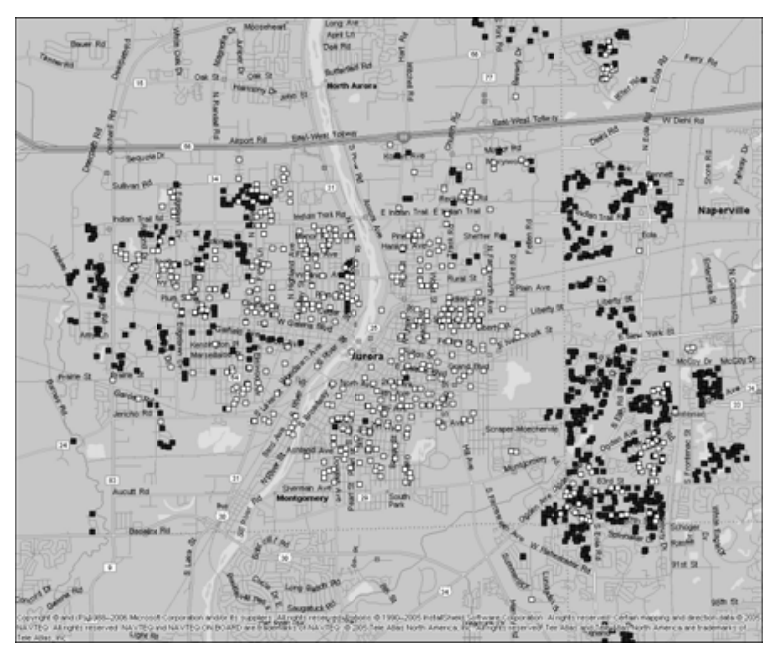

Figure 6. Affordability of Homes Sold in Aurora

\section{MapPoint Connected, Location-enabled Projects}

Rapid growth in the use of smart phones and pocket PCs is resulting in a large market for connected, location-enabled applications. Development of such applications is made much easier by advances in Visual Studio 2005, including development of mobile applications on a pocket PC emulator. This emulator is built into Visual Studio, thus eliminating the need to develop and test mobile applications directly on the device. Students have developed store locators with route and directions for a major retail firm, and are developing additional mobile applications at the time of the writing of this paper.

\section{SUMMARY}

As evidenced by the projects described in this paper, it is clear that businesses are becoming quite interested in developing solutions to specific business problems using the capabilities of GIS. This, in turn, points out the need for business schools to add courses in business applications of GIS to their curricula. The most logical department to offer such courses would be the business school's computer information systems department. NIU's OM\&IS Department has been quite successful in doing so, with nearly 300 students having taken its business GIS course now in the work force. These students have a valuable combination of capabilities - a solid knowledge of business principles and an understanding of the capabilities of GIS to analyze, visualize and solve business problems.

\section{REFERENCES}

1. Born, R. G. (2002). MapPoint Graticule COM Add-in http:/www.mp2kmag.com/a70-graticule.com.add-in.mappoint.html (3 Feb 2007).

2. Born, R. G., \& Czyz, J. (2004). Targeting New Walgreens Locations. http://www.geospatialonline.com/geospatialsolutions/article/articleDet ail.jsp?id=107295\&sk=\&date=\&pageID=11 (3 Feb 2007).

3. Born, R. G., \& Schray, M. (2007). Development of Applications Using the MapPoint Web Service Helper.

http://www.academicresourcecenter.net/curriculu m/pfv.aspx?ID=6708 (3 Feb. 2007).

4. Born, R. G. (1999-2006). Business Geographics Center. http://members.aol.com/BusGeoCntr

5. Boyles, D. (2002). GIS Means Business. Redlands, CA: ESRI Press.

6. Esseks, D., Born, R. G., Hansel, M., Sokolon, M., \& Baswedan, A. (2001). Housing Choices on the Edge: The Mix of Affordability of Home Ownership Opportunities in the Cities of Two Developing Counties on the Western Border of the Chicago Metropolitan Area: Kane and McHenry.

7. Goldstein, D. (2003). The Five Major Roadblocks to GIS Gaining Corporate Market Share.

http://www.directionsmag.com/article.php?articl e_id=332\&trv=1 (3 Feb. 2007).

8. Gorr, W., \& Kurland, K. (2007). Learning and Using Geographic Information Systems, ARCGIS Edition. Boston, MA: Thomson Course Technology.

9. Holtgrewe, BJ, \& Freeze, J. T. (2002). MapPoint for Dummies. New York, NY: Hungry Minds, Inc.

10. Ormsby, T., Napoleon, E., Burke, R., Groessl, C., \& Feaster, L. (2004). Getting to Know ArcGIS $^{\circledR}$ desktop, Second Edition. Redlands, CA: ESRI Press.

11. Schray, M. (2006). Jump Start Guide for Microsoft Visual Basic 2005. Boston, MA: Thomson Course Technology.

12. Shelly, G. B., Cashman, T. J., \& Hoisington, C. (2007). Microsoft Visual Basic 2005 for Windows and Mobile Applications, Introductory. Boston, MA: Thomson Course Technology. 
The Geographic Information Systems Initiative at the Northern Illinois University College of Business

13. Thomas, C., \& Ospina, M. (2004). Measuring Up: The Business Case for GIS. Redlands, CA: ESRI Press.

14. Thota, C. (2006). Programming MapPoint in .NET, Sebastopol, CA: O’Reilly Media, Inc. 